\title{
Performance measurement and management. A literature review focused on the role played by management theories with a deep dive into the industry 4.0 environment
}

\author{
Melissa Demartini ${ }^{1}$, Paolo Taticchi ${ }^{2}$ \\ ${ }^{1}$ Centre for Sustainable Supply Chain Engineering, Department of Technology and Innovation, University of \\ Southern Denmark, Odense, Denmark (med@iti.sdu.dk) \\ ${ }^{2}$ University College London, United Kingdom (p.taticchi@ucl.uk)
}

\begin{abstract}
Purpose: The aim of this paper is to review the theoretical lenses used in performance measurement and management in a traditional and industry 4.0 environment, and to contribute to understanding the current state of research in the field and its future development.

Design/methodology/approach: This paper performs a structured review of the existing performance measurement and management literature, with the objective to investigate the current state of research, looking at popular theories in more detail; as well as to propose possible avenues for future consideration for the field to develop further moving forward. Particularly, this paper focuses on and identifies i) theoretical lenses that are dominating this field, ii) the role played by specific theories and the way different theories are used together and finally, iii) an in-depth dive into relevant theories for performance measurement and management applied in an industry 4.0 environment.

Findings: Key findings highlight the growing number of publications, leading Authors, and journals where research is published. The findings also include the identification and detailed analysis of the most popular theories leveraged by scholars also in reference to research methodologies. A thorough analysis of Industry 4.0 performance measurement and management is then carried out, as this is one of the identified emerging themes in the research field. Findings here include the identification of relevant research and the suggestion of significant theories that can help build this specific body of knowledge.

Originality: This research offers a key contribution by providing a powerful "theoretical toolkit" to researchers and practitioners working in performance measurement and management and industry 4.0 fields.
\end{abstract}

Keywords: performance measurement and management, industry 4.0, management theories, literature review, research agenda

\section{INTRODUCTION}

The importance of performance measurement and management (PMM) has long been recognised by academics and practitioners from a variety of disciplines, from operations and engineering through to accounting and economics (Smith and Bititci, 2017; Mura et al, 2018; Bourne et al, 2018; Modell 2019; Kotkova Striteska and Zapletal, 2020). Over the years, a number of structured literature reviews have highlighted the evolution of this research field (Neely, 2005; Taticchi et al., 2010; Bititci et al., 2012) and guided the work of scholars. The work of Neely, (2005), further updated by Taticchi et al. (2010), provided an in-depth review of PMM research using classic bibliometric tools. Neely offered both quantitative and qualitative insights related to PMM research, trying to understand why in 2005 "the field of PMM has not professionalised from an academic perspective". Neely's answer pointed to the lack of maturity of the field and identified the focus of many scholars on a single framework (the Balanced Scorecard) as excessive, and potentially a limitation in the evolution of the research field. This point was further investigated five years later by Taticchi at al. (2010), who provided a structured literature review highlighting the evolution of PMM frameworks and identified three different clusters: i) integrated frameworks, ii) models to face specific issues in PMM, and iii) other relevant models for PMM system design. Moreover, Taticchi et al. (2010) agreed with Neely regarding the immaturity of the PMM field, underlining that in 2010 only ten PMM articles were cited more than 30 times. Bititci et al. (2012) added to the research outlooks set by Neely (2005) and Taticchi et al. (2010), highlighting the importance of developing PMM frameworks aligned to fast changing business contexts characterised by environmental issues and new business model, and the importance of developing specific research for small and medium enterprises (SMEs).

In 2012, Franco-Santos et al. analysed the effects of contemporary PMM systems through the lens of theories. They highlighted the lack of theoretical foundations in PMM research and therefore, the need to use theories in the design of PMM systems. This result was once more aligned with the outlooks of Neely (2005) and Taticchi et 
al. (2010), which highlighted the immaturity of PMM. However, the limited integration of management theories is not a unique issue of the PMM field, but a common problem of several new/growing research field - e.g., sustainable supply chain management (Seuring et al 2020, Touboulic and Walker, 2015; Carter et al., 2015). Indeed, theory represents the keystone of knowledge production (Handfield and Melnyk, 1998) and therefore attention needs to be paid to its application and development when attempting to evaluate any academic field. Recent papers focused on PMM have gone in the right direction. Okwir et al. (2018) recognised complexity theory as an important one to assess the effectiveness of PMM systems and have identified four system properties (ontological, teleological, genetic, and functional) that can be used to understand complexity in PMM. Moreover, Pinto (2019) suggested the use of Stakeholder and Paradox theories to design PMM systems that encourage a more complex, long-term, holistic, balanced approach to management. Another important and recent contribution was provided by Nudurupati et al. (2020), who remarked on the need to develop PMM frameworks that can quickly adapt to environmental changes and business trends. In this context, five key trends have been identified as the most relevant: i) Emerging Technologies (in line with the "Industry 4.0" concept); ii) Networking and Collaboration; iii) Servitisation and Value Co-creation; iv) Innovation \& Knowledge Work; v) Environment \& Sustainability.

In this paper, the Authors offer a specific focus on the first trend identified by Nudurupati et al. (2020) - "Industry 4.0 " - as this area has been one of the most frequently discussed and analysed topics in operations and supply chain management (Liao et al., 2017). The term "Industry 4.0" refers to new production patterns, including new technologies, productive factors and labour organizations (Demartini et al., 2019). These new patterns are completely changing the production and organizational processes, and the relationship between customer and companies with relevant effects on supply and value chains. Even though most of the innovations are still in an embryonic stage, they are on the agenda of many organisations and therefore of interest to management scholars and practitioners. One fundamental aspect of Industry 4.0 is the amount of data that is generated which in turn needs to be managed (Frederico et al., 2019) and analysed in terms of impact on traditional PMM systems. Sardi et al. (2020) argued that big data and data analysis need to be carefully managed and integrated into PMM in order to gain competitive advantage in the current business environment. Managing big data is set to become a key factor in generating new capabilities, innovation, and value in companies (Kamble et al., 2020).

Building on previous research and emerging trends (specifically, Industry 4.0) in the PMM field, and as a result of the research gaps highlighted by Neely (2005) and Taticchi et al. (2010) in relation to the immaturity of PMM, as well as the lack of theoretical underpinning underlined by Franco-Santos et al. (2012), the Authors of this paper provide an updated review of the literature. The proliferation of research on PMM since 2012, when Industry 4.0 was at the dawn of its development, further emphasised the need for a holistic understanding of the emerging literature.

Starting from these research gaps, the purpose of this study is to further understand the theoretical underpinnings of PMM literature, providing an accurate analysis of:

- The main theories adopted in PMM research;

- The role played by theories and the way multiple theories are applied;

- The link between theories and the research methods used by scholars;

- Specific theories for PMM applied in an Industry 4.0 environment.

In line with similar studies in other disciplines (Shook et al., 2009; Ketchen Jr. and Hult, 2011), this research offers a key contribution by providing a powerful "theoretical toolkit" to researchers and practitioners facing the challenge of rethinking PMM in a traditional and/or 4.0 industrial environment. This paper relies on a meticulous narrative and a systematic literature review (Tranfield et al., 2003), which captures qualitative evidence from literature and rigorous facts. Section 2 presents the methodology adopted to review the literature, while Section 3 identifies the most relevant theories and datasets applied for a traditional and Industry 4.0 PMM, along with an indepth analysis of the findings. Section 4 discusses the key findings from this research and sets out an agenda for further work. Finally, conclusions are drawn in Section 5.

\section{RESEARCH METHODOLOGY}

In this research, three datasets have been used with different scopes. The first dataset used in this paper (from now on called the "Dataset 1: comprehensive dataset") was constructed from the Scopus database as it is one of the most consistent repositories of business and management papers. The dataset was populated by identifying scientific articles containing the words "performance measurement" in the title, keywords or abstract. Moreover, the following filters were applied: 
- Language: English;

- Type: Article or Review;

- Scopus subject areas: Business Management and Accounting, and Engineering - as considered relevant for this study.

The search resulted in 7694 papers published between 1970 and 2019 . The analysis of the comprehensive dataset with bibliometric tools allowed the identification of:

- The distribution of publications over time;

- The top journals where PMM research is published;

- The most prolific scholars;

- The most frequently cited PMM works.

Following this high-level analysis, the Authors decided to study in greater depth the most popular papers published in the last twenty years (2000-2019), with the goal of developing a granular investigation. A time series analysis was developed by dividing the dataset into four time series of five years, and a second dataset was built with the twenty most popular articles of each period (a total of 80 articles identified based on number of citations). This second dataset (from now on called the "Dataset 2: relevant dataset") is particularly representative of the PMM body of knowledge as popularity of papers (measured through the number of citations) is a proxy of scientific relevance and impact (Aksnes et al., 2019). The key PMM themes prevailing in the four time periods were recognised by applying a social network of keywords. Then, with the goal of understanding the role played by management theories in PMM research, the Authors searched the relevant dataset and mapped all theories. A framework to provide a characterisation of the theories in use was developed (see Table 1).

\begin{tabular}{lll}
\hline Grouping & Dimensions & Rationale (identify -) \\
\hline $\begin{array}{l}\text { 1. Analysis of theories in } \\
\text { use }\end{array}$ & Most frequently used theories & Relevant theories \\
& $\begin{array}{l}\text { Time distribution of most frequently used } \\
\text { theories }\end{array}$ & Trends in the use of theories \\
& $\begin{array}{l}\text { Most frequently used theories in the top PMM } \\
\text { journals }\end{array}$ & $\begin{array}{l}\text { Relevant theories in top } \\
\text { PMM journals }\end{array}$
\end{tabular}

2. Analysis of the most relevant theories
In combination with which research methodology the theory is applied*

Which theories are used together?
Applicability of the theory

Synergism between theories

*As defined in Figure 1.

Table 1 - Framework used to characterise theories in use

A thorough analysis of the relevant dataset allowed the identification of:

- $\quad$ The key PMM themes prevailing in the four-time periods;

- The theories used in PMM research, their time evolution and editorial positioning;

- Insights on the use of specific theories in combination with specific research methodologies (research methods classified using the framework proposed by Taticchi et al. (2005) - see Figure 1);

- The applicability of theories and possible synergies. 


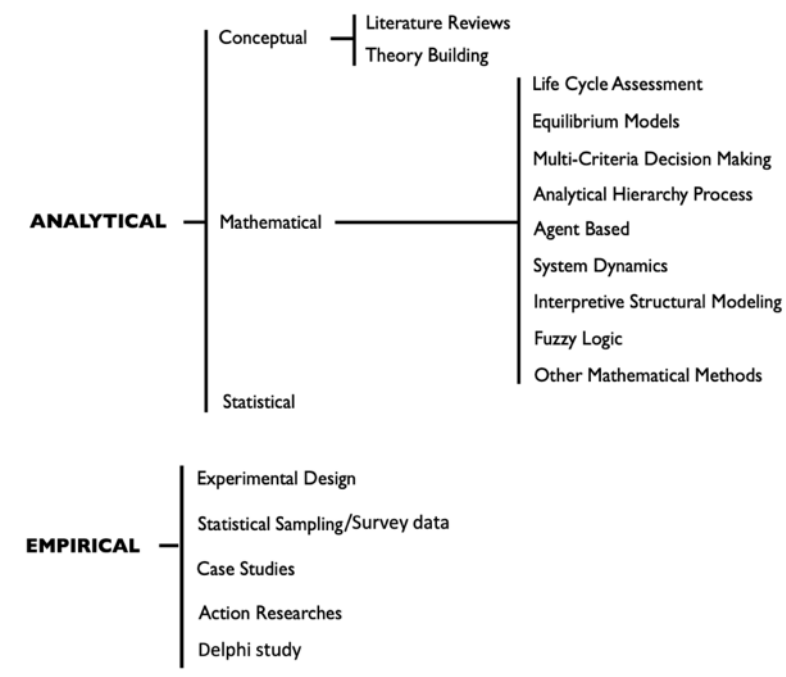

Figure 1 - Framework used for classifying research methods

Research methods were classified into two macro categories - analytical and empirical - and further divided into 19 subcategories as presented in Figure 1. It is important to clarify that 1) the Delphi study was added to the Empirical methodologies category as it was a recurring methodology, and 2) Statistical sampling was renamed "Statistical sampling/survey data" for the purpose of clarity. When mixed methods were used, the "dominant" method was identified by following the recommendations of Creswell and Plano Clark (2011) who define "dominance" based on which method is more central to the paper.

Then, a third dataset (from now on called the "Dataset 3: industry 4.0 dataset") was built starting from the Dataset 1 by identifying PMM articles with a focus on industry 4.0 ("industry 4.0 " in the title, keywords or abstract was added as criterion). The Industry 4.0 topic has been expanded as it has been recognised as one of the most important themes of the last five years (this will be further explained in findings in Section 4, Figure 8). This led to the identification of 29 papers published in the period 2016-2019. This dataset has been analysed to map specific theories for PMM in an Industry 4.0 context.

Figure 2 depicts an overview of the review protocol and dataset creation for this paper.

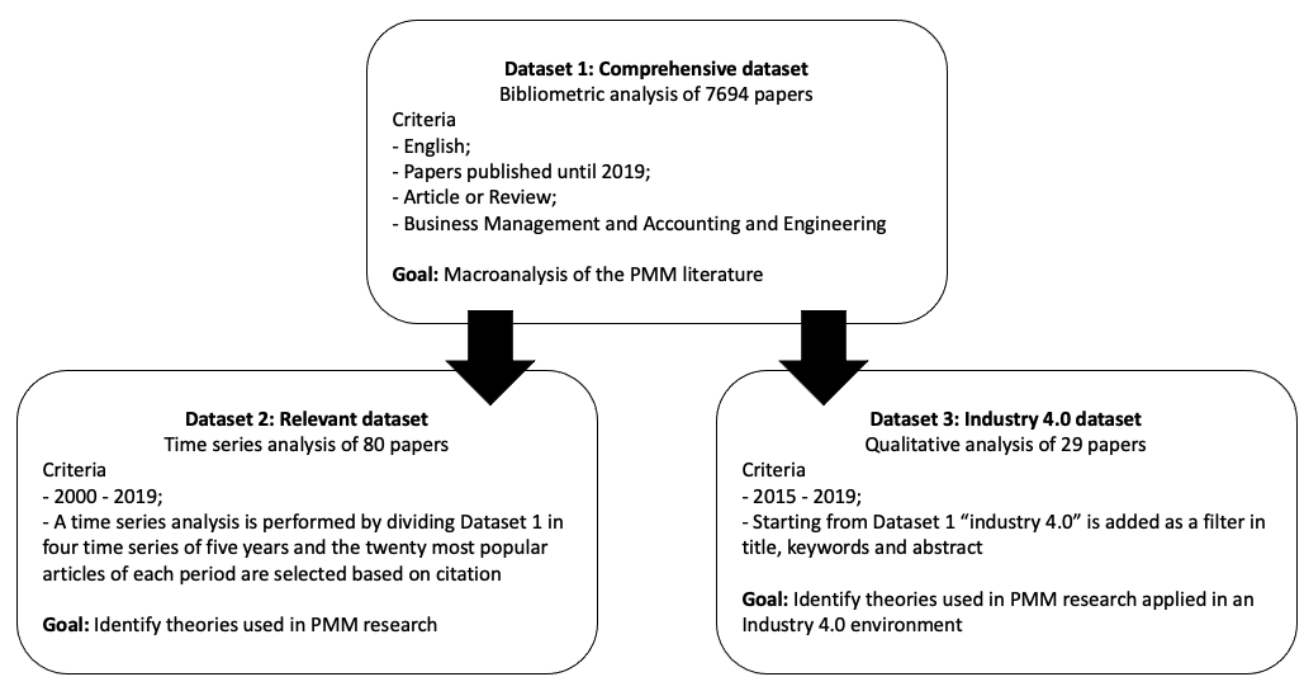

Figure 2 Overview of the review protocol and dataset creation 


\section{FINDINGS}

In this section, findings of the literature review are presented and organised using the structure of the three different datasets (Dataset 1: Comprehensive, Dataset 2: Relevant and Dataset 3: Industry 4.0).

\subsection{Dataset 1: Comprehensive dataset}

The systematic review of the literature performed by the Authors leads to the following findings. Figure 3 presents the distribution of publications over time, which shows stable growth within the PMM research field. Table 2 presents the top 10 journals where PMM research was published. While Figure 4 shows that five scholars emerge as particularly prolific by considering the number of publications (Neely, A., Bourne, M., Gunasekaran, A., M.; Ukko, J. and Bititci, U.S.).

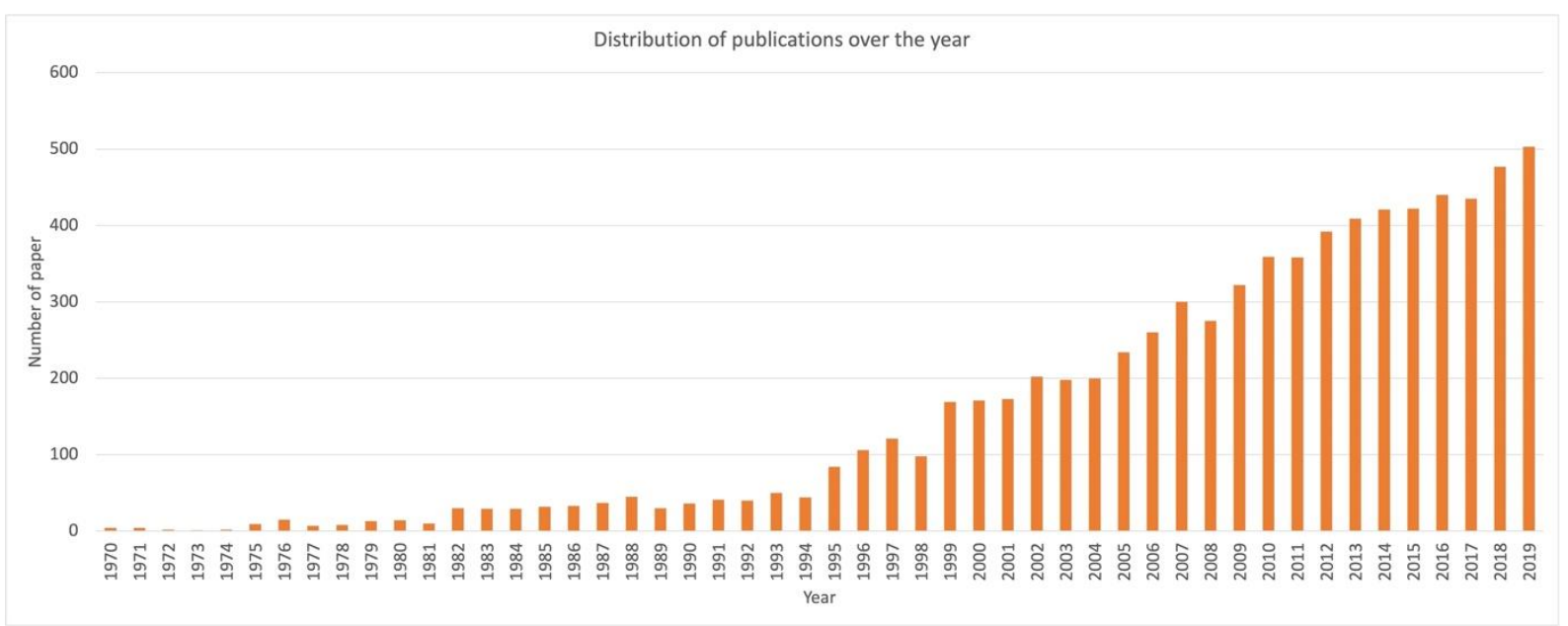

Figure 3 Distribution of publications over the year

\begin{tabular}{ll}
\hline \multicolumn{1}{c}{ Journal Title } & $\begin{array}{l}\text { Number of } \\
\text { Publications }\end{array}$ \\
\hline International Journal of Productivity and Performance & 191 \\
Management & 136 \\
Measuring Business Excellence & 132 \\
International Journal of Operations and Production Management & 114 \\
Benchmarking & 99 \\
Transportation Research Record & 90 \\
International Journal of Business Performance Management & 86 \\
International Journal of Production Economics & 84 \\
Management Accounting Research & 81 \\
International Journal of Production Research & 81 \\
Production Planning and Control & \\
\hline
\end{tabular}

Table 2 - Top ten journals by number of PMM publications 


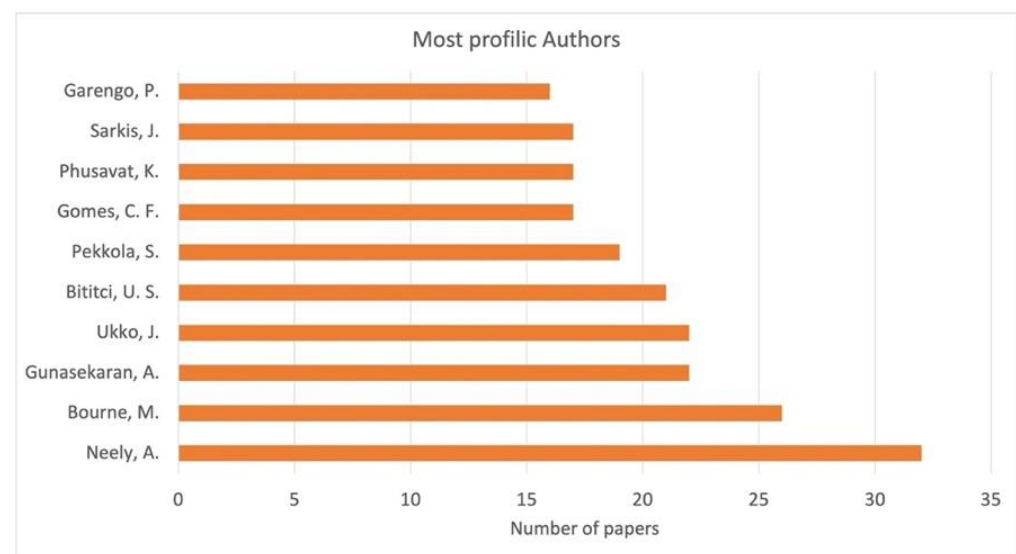

Figure 4 - Top ten Authors by number of PMM publications

The five lead authors identified have somewhat similar disciplinary backgrounds - operations management (Neely, Gunasekaran and Ukko) and accounting/strategic management (Bourne).

Table 3 shows the ranking of the most cited works. This list is led by the work of Kaplan and Norton related to the Balanced Scorecard (BSC); this fact was also reinforced by Taticchi et al. (2010). Therefore, this is still the most cited paper over the last 28 years. It is particularly important to note that, ten years later, the number of citations related to this paper has increased exponentially. In 2010 it counted for 168 citations, today it has 6198 citations. This fact also highlights a huge gap between the first two most cited papers. In fact, the second most cited paper, which is also the most recent paper amongst the most cited ones - "Performance measurement in blind audio source separation" - was published in 2006 and has garnered 1439 citations to date. Finally, seven papers out of ten were published in the 1990s. These facts confirm what was stated in Neely (2005) - the extensive use of "dated" frameworks as well as the predominance of a single tool, the BSC.

\begin{tabular}{|c|c|c|c|}
\hline Author & Title & Year & Citation \\
\hline Kaplan R.S. and Norton D.P. & $\begin{array}{l}\text { The balanced scorecard - measures that drive } \\
\text { performance }\end{array}$ & 1992 & 6198 \\
\hline $\begin{array}{l}\text { Vincent E., Gribonval R. and } \\
\text { Févotte C. }\end{array}$ & $\begin{array}{l}\text { Performance measurement in blind audio source } \\
\text { separation }\end{array}$ & 2006 & 1439 \\
\hline Neely A., Gregory M. and Platts K. & $\begin{array}{l}\text { Performance measurement system design: A } \\
\text { literature review and research agenda }\end{array}$ & 1995 & 1228 \\
\hline Beamon B.M. & Measuring supply chain performance & 1999 & 1216 \\
\hline $\begin{array}{l}\text { Gunasekaran A., Patel C. and } \\
\text { Tirtiroglu E. }\end{array}$ & $\begin{array}{l}\text { Performance measures and metrics in a supply chain } \\
\text { environment }\end{array}$ & 2001 & 1103 \\
\hline Dechow P.M. & $\begin{array}{l}\text { Accounting earnings and cash flows as measures of } \\
\text { firm performance. The role of accounting accruals }\end{array}$ & 1994 & 1036 \\
\hline Otley D. & $\begin{array}{l}\text { Performance management: A framework for } \\
\text { management control systems research }\end{array}$ & 1999 & 754 \\
\hline $\begin{array}{l}\text { Hervani A.A., Helms M.M. and } \\
\text { Sarkis J. }\end{array}$ & $\begin{array}{l}\text { Performance measurement for green supply chain } \\
\text { management }\end{array}$ & 2005 & 747 \\
\hline Eccles R.G. & The performance measurement manifesto & 1991 & 687 \\
\hline $\begin{array}{l}\text { Ragatz Gary L., Handfield Robert } \\
\text { B. and Scannell Thomas V. }\end{array}$ & $\begin{array}{l}\text { Success factors for integrating suppliers into new } \\
\text { product development }\end{array}$ & 1997 & 590 \\
\hline
\end{tabular}

Table 3 - Most frequently cited performance measurement works 


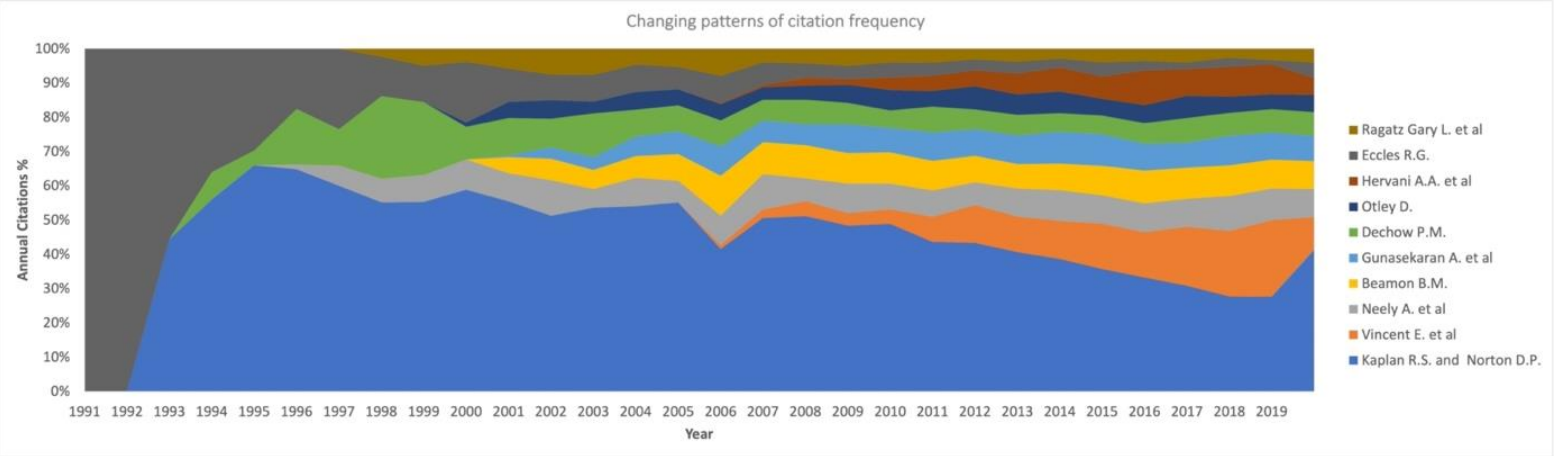

Figure 5 Changing patterns of citation frequency

These facts are also confirmed also by Figure 5 which represents an interesting analysis conducted by taking into consideration the citation frequency over time. Figure 5 presents the trend over time for the ten most frequently cited works, it is remarkable to note their stability of these works in terms of their continuing appearance in the citation rankings. Only one paper, Eccles (1991), shows a significant decreasing trend in citations over time.

\subsection{Dataset 2: Relevant dataset}

The review of particularly relevant literature leads to several insights. The dataset consists of 80 papers published between 2000 and 2019 for a total of 25.252 citations. Figure 6 depicts the distribution of the relevant database over the years - it shows that the most cited papers were published in 2005, 2012 and 2015. In 2019 just one paper relating to Industry 4.0 (Horváth and Szabó, 2019) entered the database of the most cited paper.

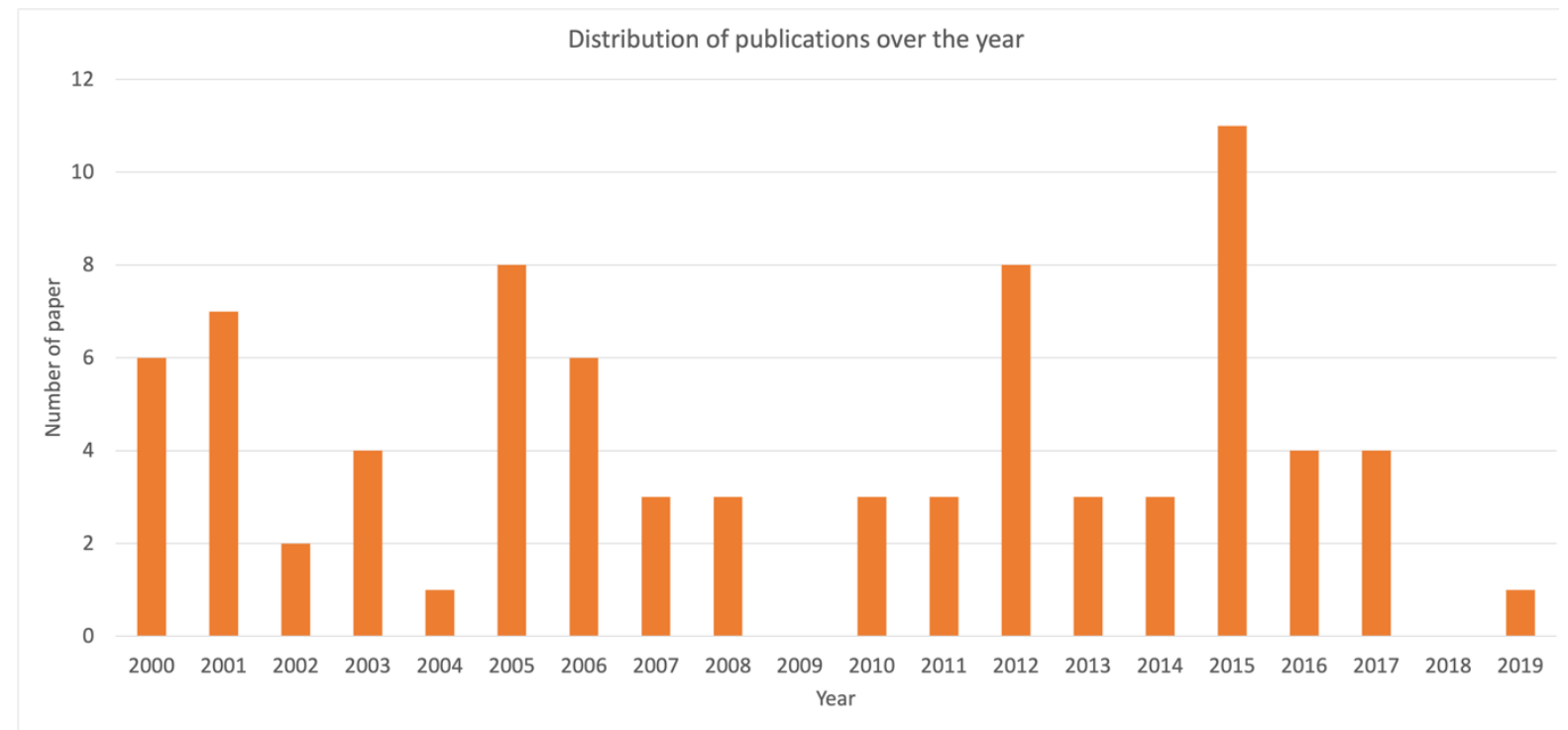

Figure 6 Distribution of publications over the years

Figure 7 shows the ranking of the journals in which the most cited papers were published (in terms of number of publications): International Journal of Operations and Production Management ( 7 papers) leads the list, followed by International Journal of Production Economics (5 papers) and International Journal of Production Research (5 papers). It is interesting to note that the articles are distributed between supply and accounting fields with the first category prevailing. This clearly indicates the technical-management orientation of the analysed scholars despite their business/accounting perspectives. This fact is also consistent with Figure 4. 


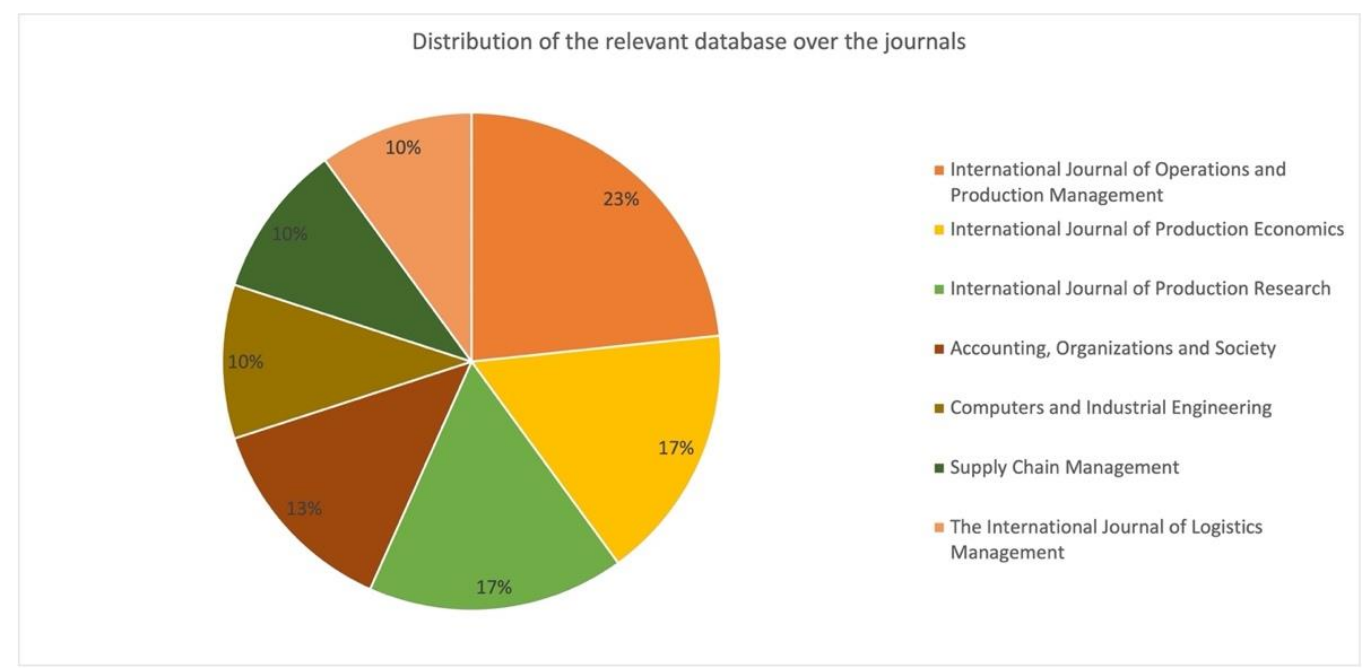

Figure 7 Distribution of the relevant database over the journals

When analysing Figure 7, it is possible to note that the International Journal of Operations and Production Management (IJOPM) provides the highest number of papers. This is in line with the transdisciplinary objectives of the journal, which as stated in its aims and scope, and investigates the following areas: opportunities, challenges, and frontiers of developing and implementing strategies, systems, processes and practices in operations and supply chain management both theoretically and practically.

The International Journal of Production Economics (IJPE) is the second journal in which the most cited papers were published. The IJPE focuses mainly on topics relating to the interface between engineering and management. Despite not explicitly mentioning focus on performance in their aims and scope the focus on performance, and stressing more the impact of the economic environment, the journal represents an important outlet for PMM studies. Finally, the International Journal of Production Research (IJPR), aims to disseminate research related to real-life applications as well as fundamental techniques to solve complex decision problems that arise in design, management and control of production and logistics systems.

Figure 8 presents a social network of keywords for the relevant dataset highlighting the following prevailing themes in PMM research.

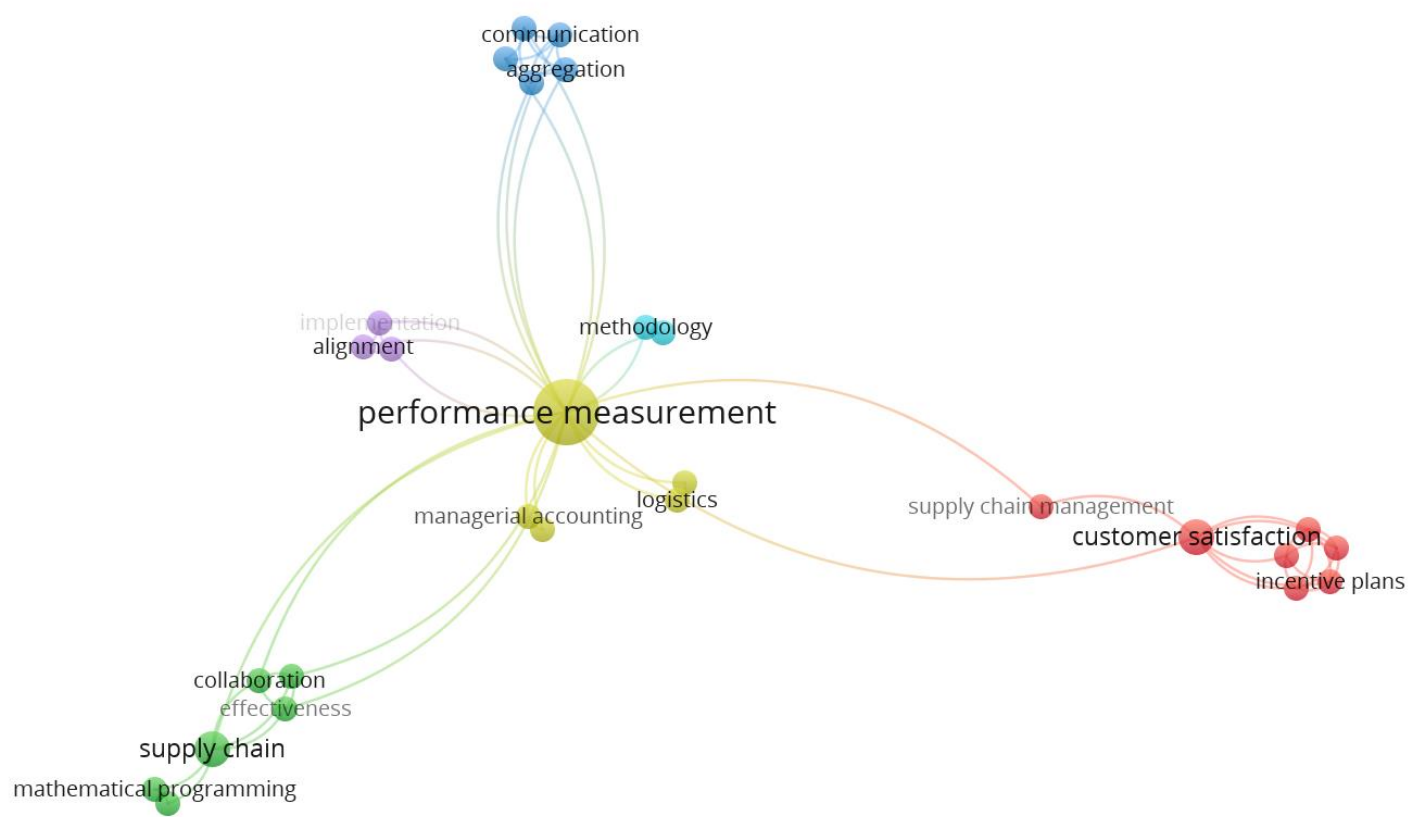

(a) Keyword social network analysis, time period 2000-2004 


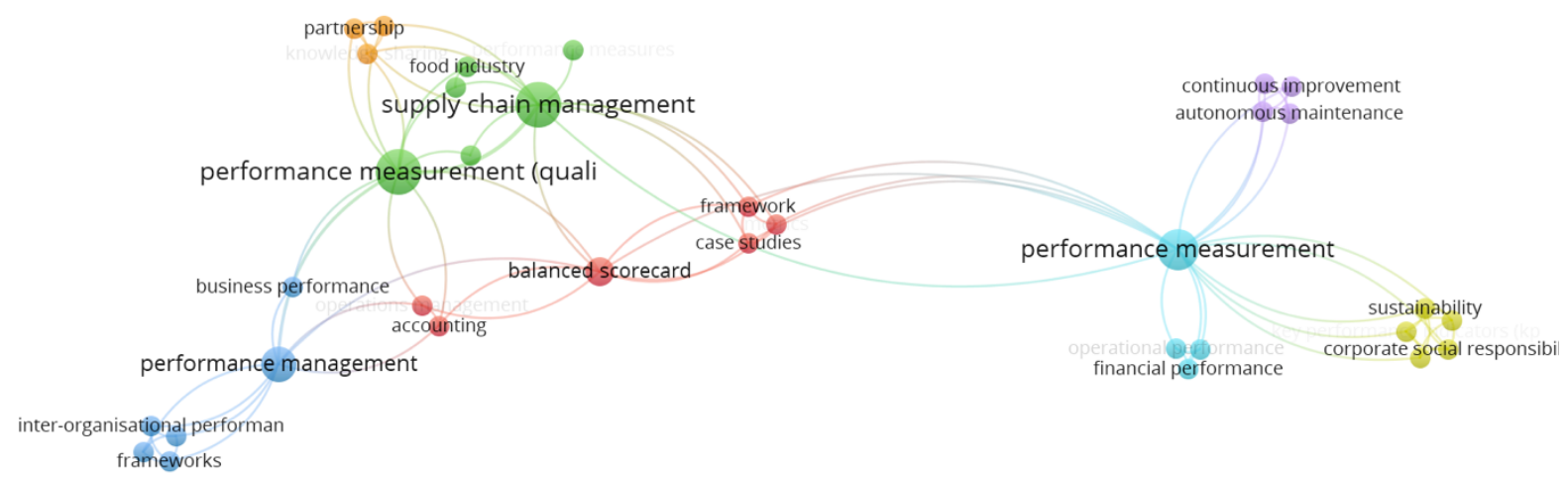

(b) Keywords social network analysis, time period 2005-2009

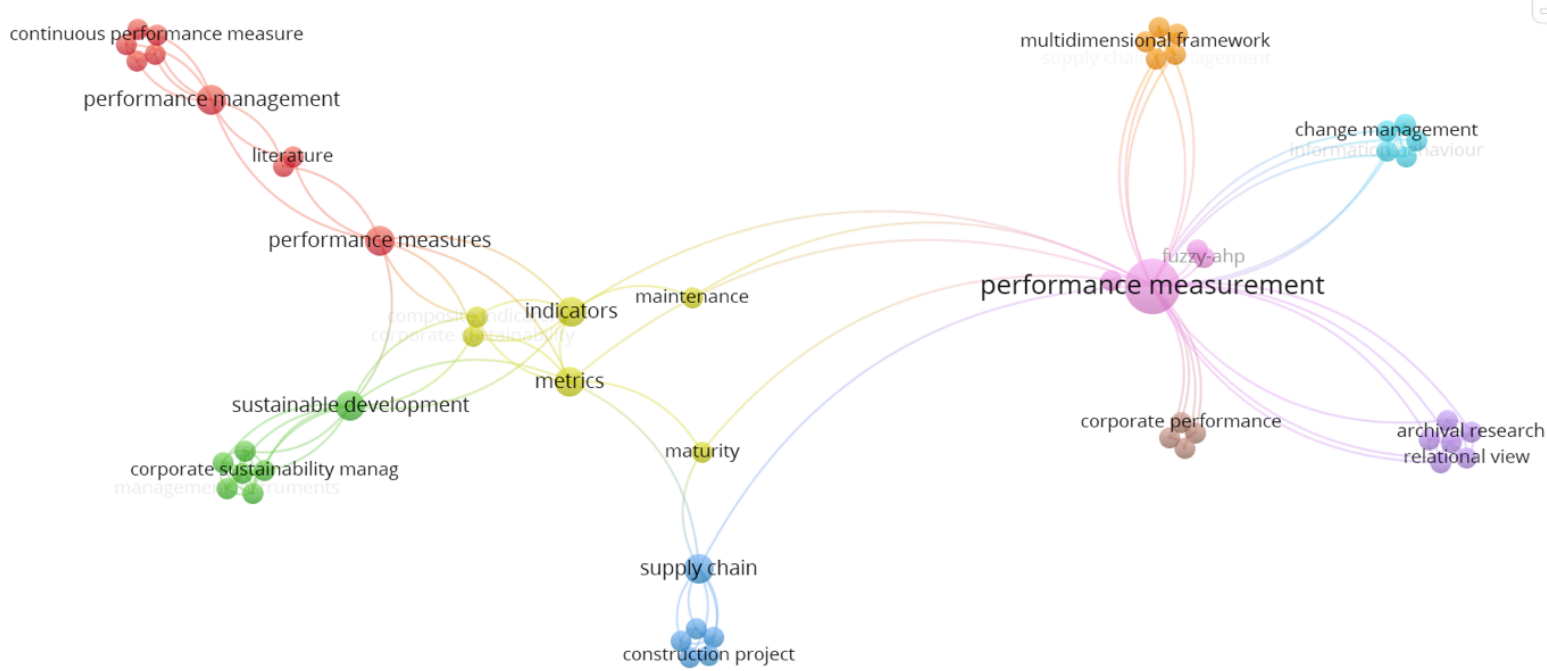

(c) Keywords social network analysis, time period 2010-2014

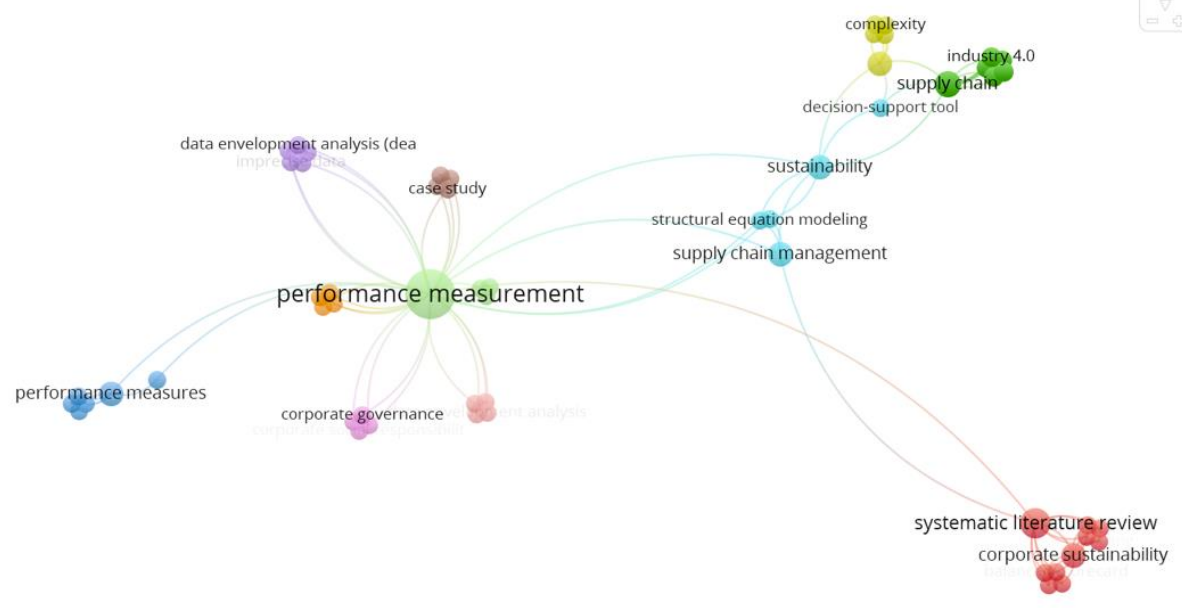

(d) Keywords social network analysis, time period 2015-2019

Figure 8 Keywords social network analysis

As previously mentioned, Industry 4.0 and digitalization emerged as key topics of the last time series. It is also important to highlight the leading role and rise of sustainable development and corporate sustainability from 2005 
up to today. Neely in 2005 performed a social keywords analysis which highlighted the following prevailing themes: balance scorecard, strategy, productivity, quality, data envelopment analysis (DEA) and health care. All of these topics recurred in this work as well, with the exception of health care. Another theme that emerged in this review as one of the most analysed industrial sectors in the time period 2010-2014, but was not listed by Neely (2005), was construction. A particular focus has also been put on strategic topics such as corporate governance and corporate performance in the last two time periods (2010-2019). Based on these results, it is possible to state that the main topics remain quite similar to what emerged in 2005, with an important shift towards sustainable and digitalization research themes, as is also highlighted by Nudurupati et al. (2020). This result meets the call proposed by Neely (2005) and Bititci et al. (2012), which asked scholars to develop research and frameworks more aligned to a business environment.

Finally, The Authors identified the most used theories in PMM (Table 4). Agency theory, Stakeholder theory, Resource-based view, Contingency theory, Institutional theory, Complexity theory, Information processing theory, Transaction cost economics, Dynamic capabilities theory, Relation view theory and Resource dependence theory are the most used in PMM research. Combined, these theories represent $69 \%$ of the total theories.

\begin{tabular}{ccc}
\hline Theory & $\begin{array}{c}\text { Frequency } \\
{[\%]}\end{array}$ & $\begin{array}{c}\text { Cumulative frequency } \\
{[\%]}\end{array}$ \\
\hline Agency theory & $12 \%$ & $21 \%$ \\
Stakeholder theory & $9 \%$ & $28 \%$ \\
Resource based view & $7 \%$ & $35 \%$ \\
Contingency theory & $7 \%$ & $42 \%$ \\
Institutional theory & $7 \%$ & $47 \%$ \\
Complexity theory & $5 \%$ & $52 \%$ \\
Information processing & $5 \%$ & $57 \%$ \\
theory & $5 \%$ & $61 \%$ \\
Transaction cost economics & $4 \%$ & $65 \%$ \\
Dynamic capabilities theory & $4 \%$ & $69 \%$ \\
Relation view theory & $4 \%$ & \\
Resource dependence theory & &
\end{tabular}

Table 4 - Most relevant theories in PMM research

Table A1 is an overview of each theory presented from most frequently used to least frequently used.

Figure 9 shows the time evolution of the identified theories, illustrating a clear emergence of a growing body of literature on PMM, including a steep increase between 2000 and 2013. It seems that out of all the theories in PMM, Agency theory and Resource-based views have grown much faster than the others in previous years, showing a significant peak in 2013. Additionally, in 2019, the most cited papers didn't refer to any theories, following a noticeably decreasing trend from 2014 up to 2019. This fact could be explained by considering that the relevant dataset is composed of the most cited papers for each time series, with the last time series (2015-2019) being more penalised (in terms of the number of citations) by being closer to present day, and therefore it could show partial unreal trends (as citations increase over time). 


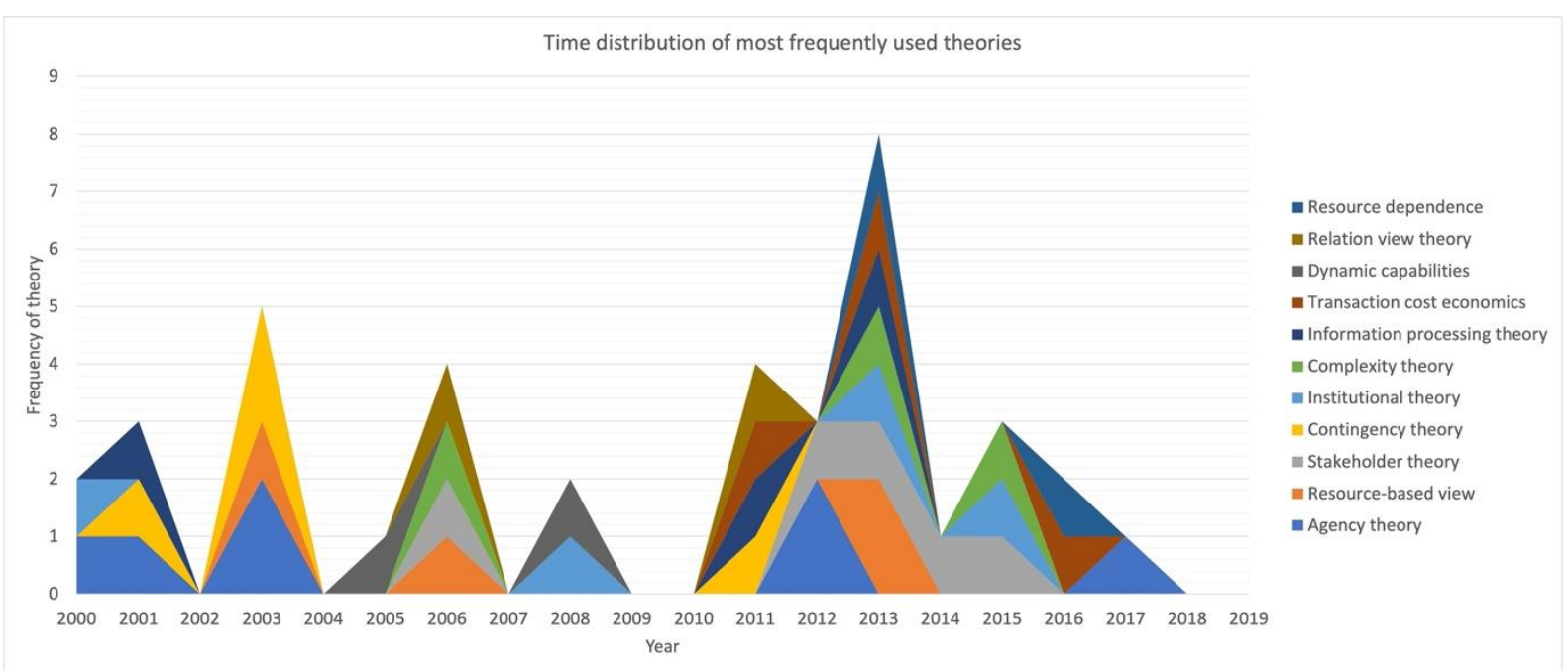

Figure 9 - Time distribution of most frequently used theories

The top three journals in terms of number of papers in which theories are published are the Business Process Management Journal, Accounting Review and IJPE. The full classification of publications is shown in Figure 10. It is interesting to note that the articles are often distributed between accounting and business management, and supply, with a predominance of the first class. This is in contrast with what emerged in Figure 7. Therefore, it seems that when analysing all the papers of the relevant dataset the majority of the studies rely on to supply topics. Yet, when analysing solely papers related to management theories, the focus shifts to accounting studies. Additionally, another interesting fact is that $61 \%$ of the studies reviewed have no explicit theoretical underpinning.

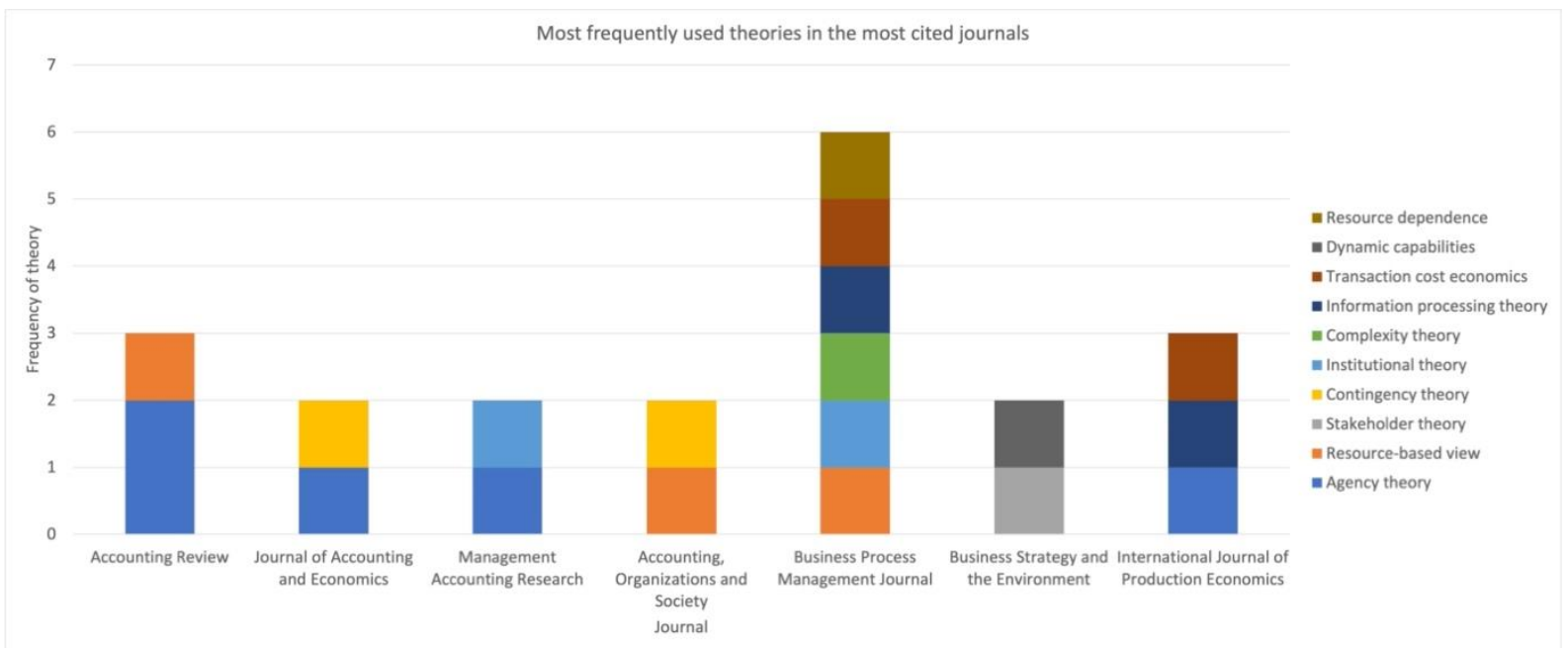

Figure 10 - Most frequently used theories in the most cited journals

Regarding the research methods, there is a dominance of analytical papers $65 \%$ (Table 5).

\begin{tabular}{|c|c|c|c|}
\hline Research & & Frequency & \\
\hline Analytical & $65 \%$ & $\begin{array}{l}\text { Literature review } \\
\text { Mathematical model } \\
\text { Theory building }\end{array}$ & $\begin{array}{l}55 \% \\
16 \% \\
29 \% \\
\end{array}$ \\
\hline Empirical & $35 \%$ & $\begin{array}{l}\text { Action research } \\
\text { Case study } \\
\text { Experimental design } \\
\text { Survey }\end{array}$ & $\begin{array}{l}4 \% \\
32 \% \\
14 \% \\
50 \% \\
\end{array}$ \\
\hline
\end{tabular}

Table 5 - Research methodology classification of papers 
The 28 literature review papers are the most used research methodology, followed by Theory building (15 papers) and Survey (14 papers). Important contributions are also provided by Case study (9 papers), Mathematical model (8 papers) and Experimental design (4 papers). Of the 28 literature reviews, only 12 papers refer to at least one theory - the most used theory for this research method is Contingency theory. Concerning the two most cited theories, Agency theory and Stakeholder theory, Agency theory has been adopted in a variety of research methods including Experimental design, Literature review, Mathematical model, Survey and Theory Building, while Stakeholder theory is mainly adopted in Theory Building research, where notably 4 papers out of 5 adopted this research method.

The Authors of this study found that different theories are often used in union, as depicted by Figure 11. It is important to underline the central role of Institutional theory, Information processing theory, Resource advantage theory, Relation view theory and Transaction cost economics as the most recurring theories in the cross theories' usage. Furthermore, some of the most used theories (i.e., Stakeholder theory, Contingency theory, Complexity theory and Resource dependence theory) are rarely used in conjunction with other theories in studying PMM.
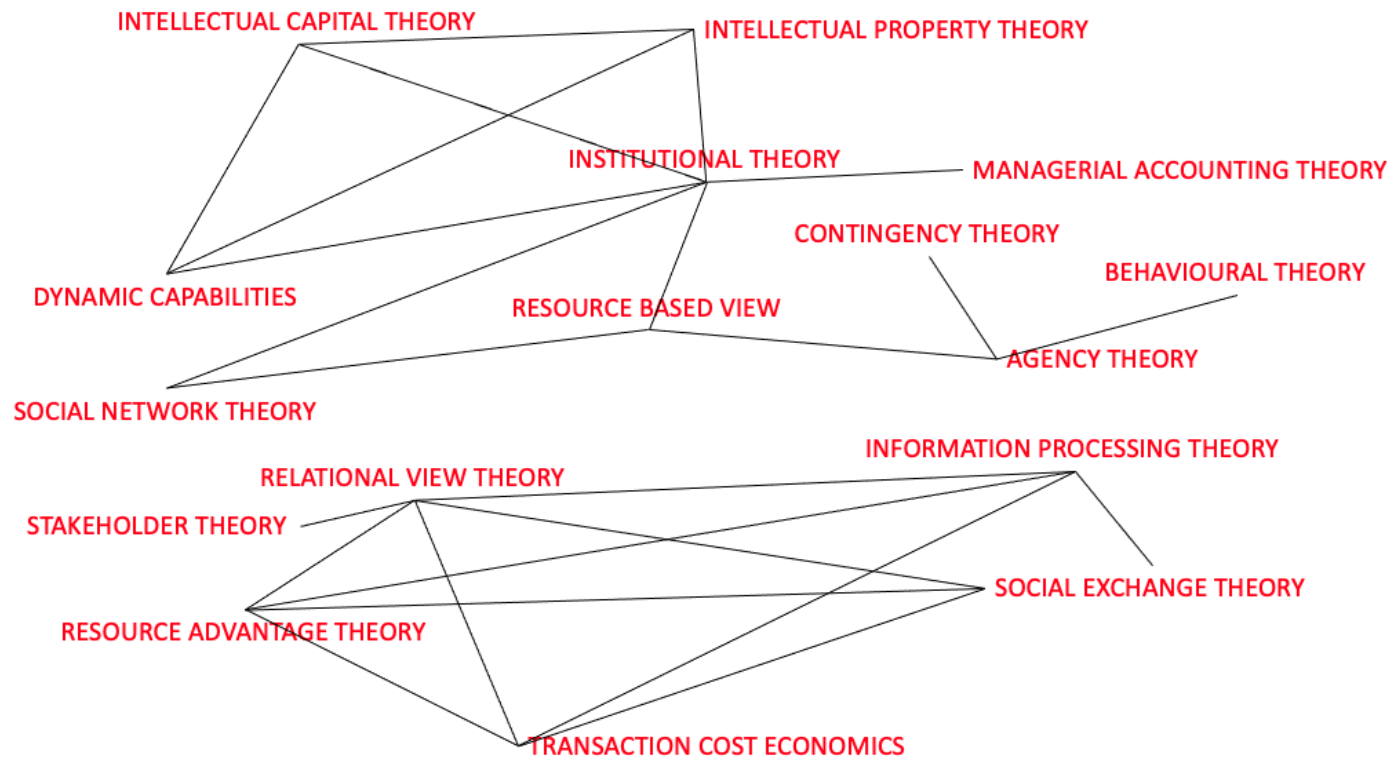

Figure 11 - Popular combinations of management/business theories in PMM research

Finally, it is interesting to note that when looking at the top three most used theories, Agency, Contingency and Resource-based view, the findings are substantially aligned, seven years later, with the results presented by FrancoSantos et al. (2012), who identified seven popular theories (four of which are also identified by this research). A detailed comparison is offered in Table 6. In both papers, the most used theory in PMM is Agency theory, and the Resource-based view ranks third. Varying between these two papers are the theories that ranked second. According to this research, the Stakeholder theory is the second most used theory, but it was not found popular by FrancoSantos et al. (2012). Therefore, it is worth noting the remarkable increase in popularity the Stakeholder theory has seen in recent years. This rise in popularity could be attributed to the fact that by adopting a stakeholder perspective, it is possible to examine a broader set of performance which reflect views of the stakeholders that are involved in the PMM, and not only the economic view (Harrison and Wicks, 2013). The growth of Stakeholder theory could also be linked to the increase of the Sustainability research topic in PMM, where the multi stakeholder perspective is a core requirement. Contingency theory and Information processing theories proved relevant for both studies, even if they decreased in importance according to this study. Several theories identified in this research were not identified as relevant by Franco-Santos et al. (2012) (i.e., Institutional theory, Complexity theory, Transaction cost economics, Dynamic capabilities theory, Relation view theory and Resource dependence theory). Therefore, it is possible to state that in the last few years (2013-2019), scholars have expanded the set of theoretical lenses to study and design the PMM research field in relation to the past. The usage of diverse theories is called by Touboulic and Walker (2015), which analysed the adoption of theoretical lenses in the sustainable supply chain management (SSCM) field. Touboulic and Walker (2015) stated that researchers in SSCM should consider testing and extending other potentially relevant theories from various disciplines, outside of the few popular lenses that have been applied to date. Even if this recommendation is related to another research field, the 
usage of diverse theoretical lenses is of particular importance in PMM, as it could indeed play a key role when investigating an immature context from different points of view.

\begin{tabular}{ccc}
\hline $\begin{array}{c}\text { Theory (Listed by popularity } \\
\text { based on this research) }\end{array}$ & $\begin{array}{c}\text { Popularity based on } \\
\text { Franco-Santos et al. } \\
\text { (2012) }\end{array}$ & Comparison \\
\hline Agency theory & {$[\# 1]$} & $=$ \\
Stakeholder theory & $*$ & $\downarrow$ \\
Resource-based view & {$[\# 3]$} & \\
Contingency theory & {$[\# 2]$} & \\
Institutional theory & $*$ & \\
Complexity theory & $*$ & \\
Information processing theory & {$[\# 4]$} \\
Transaction cost economics & $*$ & \\
Dynamic capabilities theory & $*$ & \\
Relation view theory & $*$ & \\
Resource dependence theory & &
\end{tabular}

Table 6 - Most relevant theories: comparison with the findings of Franco-Santos at al (2012)

\subsection{Dataset 3: Industry 4.0 dataset}

Industry 4.0 rises as one of the emerging themes of the last five years in PMM research (Figure 8). With the goal of identifying relevant theories for PMM applied in an Industry 4.0 environment, the Authors analysed the industry 4.0 dataset and mapped all theories. The dataset is composed of 29 papers published between $2016-2019$.

A total of seven papers were found to have a theoretical underpinning for a total of 15 different theories used, as presented in Table 7.

As highlighted by Table 7, the most used theory for PMM in an Industry 4.0 environment is Contingency theory. This is not surprising as it is an organizational theory based on the concept that managers have to make decisions in contingent environments, therefore they need to be flexible in adapting strategies to specific dynamic situations. In this regard, Taylor and Taylor (2014) stated that a PMM 4.0 implementation differs in large firms and SMEs due to their specific contingency factors: strategy, information system and quality management. Additional contingency factors for PMM in a 4.0 environment include: information technology (IT), technology, environmental dynamism and organisational structure. Klovienè and Uosyte (2019) consider technology as the main contingency factor influencing PMM in a digital environment due to the high level of uncertainty related to its implementation. Technology is one of the most impacted factors by the fourth industrial revolution. The primary types of technology that influence the adoption and utilisation of PMM systems include: technological complexity, task uncertainty and technological interdependence (Wadongo and Abdel-Kader, 2014). These factors have to be taken into account by researchers in order to develop new frameworks, and by practitioners in order to improve the success in PMM implementation. Information and Communication Technology (ICT) is another important contingency factor that has a primary role in a PMM 4.0 implementation - it is responsible for collecting and managing data for performance measurement. Large amount of data would be generated, and the complex nature of such data, along with its heterogeneity, make it difficult to measure completeness and data accuracy. Furthermore, ICT level of adoption is strictly dependent on size, resources allocated and strategic alignment (Finn et al., 2006). This approach requires huge investments in IT, supply chain and customer service.

Lucianetti et al. (2018) adopted a contingency theory to highlight the importance of an alignment between organizational strategy and PMM in a digital environment. This means that when companies decide to implement 
a PMM 4.0 strategy they have to be aware of the technological and organizational transformations required. Businesses have to consider and map existing capabilities, market dynamics and corporate strategies. Another fundamental organizational aspect that has to be carefully analysed is human resources. The implementation of an innovative PMM system requires specific skills and competences. Companies that are able to secure trained human resources would be better positioned in the competitive landscape (Agrawal et al, 2018). Therefore, changes in organizational structure as well as human resources have to be carefully managed. Companies primarily need employees with skills and knowledge in IT, and if these skills are not available, they have to train their employees to be prepared for the impending digital transformation (Raj, et al 2020).

In addition to contingency theory, another theory that appears to have great potential in the context of framing PMM 4.0 problems is control theory, which stresses the importance that actions of all systems should be in sync with the overall goals and objectives of an organization (Barrows and Neely, 2012; Mohammadi et al, 2018). A very recent paper by Nudurupati, Garengo and Bititci (2021) has leveraged control theory to analyse how new business trends (including Industry 4.0) affect PMM within organizations.

\begin{tabular}{cl}
\hline Paper & \multicolumn{1}{c}{ Theory/Theories used } \\
\hline (Kibira et al, & $\begin{array}{l}\text { Control theory, Decision } \\
\text { theory, Information } \\
\text { theory, Queuing theory, } \\
\text { Inventory theory }\end{array}$
\end{tabular}

(Oses et al, Linear regression theory 2016)

(Strzelczak, Resource dependence 2018) theory, Systems theory, Mereotopology theory

(Lucianetti et Contingency theory al, 2018)

(Klovienè and Uosyte, 2019)

(Sahlin and Angelis 2019)
Strategy theory, Probabilistic theory, Dynamic capability theory
Research insights

Smart manufacturing systems can deliver awareness, agility, productivity, and resilience within the production process by exploiting the ever-increasing availability of real-time manufacturing data. In this paper, a review of the different PMM tools and methods based on multiple theories is provided in order to understand their applicability in an industry 4.0 environment. Authors propose future research for assessing and improving manufacturing performance in an uncertain, multi-objective operating environment based on real time measurement and assessment.

In this paper linear regression theory is adopted to frame a model for the energy consumption of the injection machines in a manufacturing facility. In fact, industry 4.0 methodological advancements based on continuous analytics and on the sensorisation of manufacturing lines make it possible to design and develop integrated systems for measurement and verification of the impact of implemented energy conservation measures.

This paper investigates the use of PMM in the mechanisms of production internet. Reference architecture is elaborated by reflecting on the functional scope of production internet and its ecosystem structuring. Resource dependence theory is used to define production internet as it is expected to reduce the uncertainty of using alien resources; while system theory and mereotopology theory are used to frame the ecosystem perspective.

This work adopts contingency theory to explore the influence of factors such as environmental uncertainty, decentralization, and organisational strategy on the adoption of advanced manufacturing tools and advanced managerial practices.

The aim of this paper is to understand how PMM systems need to evolve in order to be successful in an Industry 4.0 environment. Contingency theory is used to explain the importance of developments in PMM systems in the context of the industrial revolution. From the research it emerges that the influence of technology and environment on PMM is a very important contingent factor in an Industry 4.0 environment. This study explores how PMM research has incorporated dynamic aspects and digitalization prevalent in rapidly changing and competitive environments. Strategy theory is adopted to describe how well-defined measures and indicators provide input to both accounting models and various strategic decisions. Probabilistic theory is used to explain the uncertainty of Artificial intelligence. Dynamic capability theory is indicated as theory that should be used more in PMM research. 
(Jeble et al Resource-based view, 2019) Social capital theory
This paper focuses on the role of big data and predictive analytics and social capital on the performance of humanitarian supply chains. It explores the different performance measurement frameworks and offers a conceptual model. Resource-based view theory and social capital theory are used to frame the work.

Table 7 - Management theories used in PMM research applied in an industry 4.0 environment

\section{DISCUSSION OF FINDINGS}

This study has highlighted several challenges and benefits of applying theories in a traditional and Industry 4.0 PMM. In this sense, this study has several beneficial managerial and practical implications, as follows:

- $\quad$ PMM research has come a long way. The existing body of knowledge appears to be mature for the environment of large corporations, but less mature for collaborative environments such as those of supply chains or enterprise networks. Further research on PMM applied in an SME environment is still needed.

- Five theories emerge of particular importance for PMM: Agency theory, Stakeholder theory, Resourcebased view, Contingency theory and Institutional theory.

- $\quad$ PMM is playing a fundamental role for an industry 4.0 environment and expect research to grow accordingly. The benefits of implementing PMM systems in an industry 4.0 environment are i) to measure the impact of digitalisation projects, ii) manage the performance of several stakeholders operating in the digital ecosystems and iii) to increase transparency.

- In addition to the five theories mentioned before, the Authors suggest exploring more in depth the application of dynamic capability theory in the design of PMM for industry 4.0 environments. In fact, the theory helps to understand firms' ability to integrate, build, and reconfigure internal and external competences to address rapidly changing environments.

\subsection{Research agenda}

The review presented in this paper shows that PMM literature is rapidly evolving and despite this fact, comparatively just one study has analysed the role of theoretical lens in the PMM field. Moreover, the research community continues to be dependent on a limited number of works from a limited number of contributors. In Authors' opinion, these evidences are interrelated - theories are necessary to describe phenomena of interest and topics that have a practical relevance. Theoretical lenses can lead to a new concept or idea that can be translated in a conceptual framework (Walker et al, 2015). A reflection on theory is also practical, given that it guides research toward important questions and enlightens PMM practitioners, therefore the Authors call scholars to reflect on the important insights emerged from the wider contemporary literature on PMM.

Table 8 summarises the key suggestions for avenues of future research on PMM and PMM 4.0- these are based on the most frequently cited management theories in the field of PMM.

\begin{tabular}{|c|c|}
\hline Theory & Research agenda \\
\hline $\begin{array}{l}\text { Agency } \\
\text { theory }\end{array}$ & $\begin{array}{l}\text { To explore the design PMM (4.0) systems for supply chain to reduce issues related to lack of } \\
\text { information and control mechanism. }\end{array}$ \\
\hline $\begin{array}{l}\text { Stakeholder } \\
\text { theory }\end{array}$ & $\begin{array}{l}\text { To analyse the expectations of stakeholders and their collaboration to design PMM (4.0), and } \\
\text { organize the implementation of Industry } 4.0 \text { technologies. }\end{array}$ \\
\hline $\begin{array}{l}\text { Resource- } \\
\text { based view }\end{array}$ & $\begin{array}{l}\text { To investigate the organisational resources and capabilities necessary to design a PMM (4.0) } \\
\text { and identify potential barriers its implementation. }\end{array}$ \\
\hline $\begin{array}{l}\text { Contingency } \\
\text { theory }\end{array}$ & To explore contingency factors impacting on PMM (4.0) and related implementation efforts. \\
\hline $\begin{array}{l}\text { Institutional } \\
\text { theory }\end{array}$ & To explore the extent to which different institutional environments impact on PMM (4.0). \\
\hline
\end{tabular}

Table 8 - Research outlooks for scholars based on selected theories 
Building on the findings of this research, the Authors propose the following avenues for future research.

Traditional PMM

- Emerging themes: this work has identified a number of themes that have been central in PMM research in the last five, ten, fifteen and twenty years. Therefore, scholars are encouraged to engage with the research topics presented in Figure 8.

- Adoption of management theories into PMM research: $61 \%$ of studies reviewed has no explicit theoretical underpinning, which suggests that theoretical knowledge in PMM research is still at the modelling stage. Therefore, the Authors invite scholars to further adopt and integrate management theories into PMM research to develop new frameworks by building on the guidelines provided by this work (role played by theories, applicability and suggested combinations).

- Use of classic management theories: classic management theories such as Agency theory, Stakeholders' theory, Resource-based view, Contingency theory and Institutional theory have proved to serve well PMM research. Therefore, the Authors invite scholars to keep using these theoretical lenses and invite them to explore the use of other theories such as dynamic capability theory, decision theory and complexity theory.

PMM 4.0

- Adoption of management theories into PMM 4.0 research: the large majority of studies focused on PMM 4.0 have no explicit theoretical underpinning. Therefore, the Authors invite scholars to further adopt and integrate management theories such as those popular in general PMM, and those that have shown good results when applied in Industry 4.0 environments such as Contingency theory and Control theory.

- Focus on organizational conversion and transformation stages: the shift from PMM to PMM 4.0 requires more holistic approaches because of the complexity related to the introduction of new technologies that lead to rapid business process re-engineering. The Authors invite scholars to explore the problems associated to the implementation of PMM 4.0 by giving particular attention to the different stages of change/implementation and the implications for different levels of analysis (e.g., individual level, firm level, network level).

- PMM in an industry 4.0 environment: this research shows a growing interest for this topic and therefore the Authors encourage PMM scholars to carry out further research aimed at designing new tools and frameworks for highly automated, connected and fully digitalised environments. Given the speed of technological changes, empirical approaches based on action research could be particularly effective to study industry practice in conjunction with the use of Control theory to capture the complexity of emerging trends.

\subsection{Practical Implications of this work}

This research comes with valuable information for practitioners. Table 9 summarises the relevance of findings to companies and professionals working in PMM.

\begin{tabular}{l} 
Practical implications \\
\hline PMM is key in industry to succeed: existing literature on PMM shows \\
clearly the benefits of adopting PMM systems and offers valuable \\
insights for the design and management of these type of tools. \\
Practitioners are invited to apply theoretical frameworks and tools by \\
taking into account the specificities of their business environments. \\
PMM literature is available in relation to the latest industry trends: \\
practitioners can find valuable resources in literature to implement \\
PMM initiatives in support of specific projects (e.g., sustainability, \\
supply chain, corporate governance or efficiency projects). The \\
Authors invite practitioners to keep up with the relevant literature so \\
as to continuously improve PMM initiatives
\end{tabular}

PMM systems can support industry 4.0 initiatives: industry 4.0 projects are complex in nature and call for major investments. For this reason, it emerges from this research that companies and practitioners

\section{Relevant business/management} theories

agency theory; contingency theory; resource-based view; stakeholders' theory; complexity theory; decision theory

agency theory; contingency theory; resource-based view; stakeholders' theory; complexity theory; decision theory

agency theory; contingency theory; resource-based view; stakeholders' theory; dynamic capability theory 
should plan for the design of PMM systems to control and guide the correct implementation of these initiatives.

PMM systems can be used to manage multiple stakeholders in an industry 4.0 environment and push transparency: industry 4.0 calls for unprecedented levels of collaboration which often go beyond the traditional boundaries of supply chains and industries. PMM systems can help organisations to measure and manage the performance of these complex automated, digitalised and collaborative environments by supporting decision-making with real-time relevant information and by improving the transparency of inter-firm operations. agency theory; contingency theory; resource-based view; stakeholders' theory; dynamic capability theory

Table 9 - Relevance of this research to practitioners

\subsection{Limitations of this work}

This research has some inherent limitations that can be seen as opportunities for future research. Firstly, the literature focuses on "Business Management and Accounting", and "Engineering" fields, so PMM has been analysed considering these specific areas. The Authors have only reviewed publications in English in the forms of article and review to ensure the quality of the publications reviewed. There might be an important loss of knowledge by not including publications in other languages, conference papers, industry reports, books, and book chapters. Moreover, papers using mixed methods were analysed only based on the dominant methodology, without considering other factors such as sequence (Morgan, 2013). In future research, the Authors plan to extend these limitations.

\section{CONCLUSIONS}

This article provided a comprehensive review of PMM literature. After an initial introduction to the topic, bibliometric techniques were used to analyse the evolution of the literature. Findings highlighted the growing number of publications, leading Authors, and leading journals where PMM research is published. The Authors also provided a more detailed analysis of the relevant research published in the last twenty years by leveraging a time series analysis. Findings included the identification and detailed analysis of the theories leveraged by PMM scholars, also in reference to different research methodologies. A deep dive into PMM applied in Industry 4.0 environments was also carried out as this is one of the emerging themes in PMM research. Findings here included the identification of relevant PMM research and the recommendation of significant theories that can help build this specific field, as well as provide a research agenda for scholars. Overall, the study provides a very valuable "theoretical toolkit" for PMM researchers and practitioners who deal with the design and management of PMM systems in traditional and/or Industry 4.0 environments.

\section{REFERENCES}

- Agrawal, A., Schaefer, S., Funke, T., (2018). Incorporating Industry 4.0 in corporate strategy. In Analysing the impacts of Industry 4.0. Modern business environments (pp. 161-176).

- $\quad$ Aksnes, D.W., Langfeldt, L., Wouters, P. (2019). Citations, Citation Indicators, and Research Quality: An Overview of Basic Concepts and Theories. SAGE Open, 9(1), p.215824401982957.

- Alexander, A., Kumar, M., Walker, H. (2018). A decision theory perspective on complexity in performance measurement and management International Journal of Operations and Production Management, 38 (11), pp. 2214-2244.

- Barrows, E., Neely, A.D. (2012). Managing performance in turbulent times: analytics and insight. Hoboken, N.J.: Wiley.

- Bititci, U., Garengo, P., Dörfler, V., Nudurupati, S. (2012). Performance measurement: challenges for tomorrow. International journal of management reviews, 14(3), 305-327. 
- Bourne, M., Franco-Santos, M., Micheli, P., Pavlov, A., (2018). Performance measurement and management: a system of systems perspective. International Journal of Production Research, 56(8), pp.2788-2799.

- $\quad$ Byrne, D.S., (1998). Complexity theory and the social sciences: An introduction. Psychology Press.

- Carter, C.R., Rogers, D.S. and Choi, T.Y. (2015), "Toward the theory of the supply chain", Journal of Supply Chain Management, Vol. 51 No. 2, pp. 89-97.

- Creswell, J. W., Plano Clark, V. L. (2011). Choosing a mixed methods design. Designing and conducting mixed methods research, 2, 53-106.

- $\quad$ Demartini, M., Evans, S. and Tonelli, F., 2019. Digitalization technologies for industrial sustainability. Procedia manufacturing, 33, pp.264-271.

- DiMaggio, P. J., Powell, W. W. (1983). The iron cage revisited: Institutional isomorphism and collective rationality in organizational fields. American sociological review, 147-160.

- Donaldson, L. (2001). The contingency theory of organizations. Sage.

- Dyer, J.H., Singh, H., (1998). The relational view: Cooperative strategy and sources of interorganizational competitive advantage. Academy of management review, 23(4), pp.660-679.

- Eisenhardt, K. M. (1989). Agency theory: An assessment and review. Academy of management review, 14(1), 57-74.

- Eisenhardt, K. M., Martin, J. A. (2000). Dynamic capabilities: what are they?. Strategic management journal, 21(10-11), 1105-1121.

- $\quad$ Finn, S., Jill, K., Maher, J. (2006). Indicators of Information and Communication Technology Adoption in the Nonprofit Sector Changes Between 2000 and 2004. Non-Profit Management \& Leadership, Vol. 16 No. 3

- Franco-Santos, M., Lucianetti, L., Bourne, M. (2012). Contemporary performance measurement systems: A review of their consequences and a framework for research. Management accounting research, 23(2), 79-119.

- $\quad$ Frederico, G.F., Garza-Reyes, J.A., Anosike, A., Kumar, V. (2019), Supply Chain 4.0: concepts, maturity and research agenda. Supply Chain Management, Vol. 25 No. 2, pp. 262-282.

- Freeman, R. E., Phillips, R. A. (2002). Stakeholder theory: A libertarian defense. Business ethics quarterly, 12(3), 331-349.

- Handfield, R. B. and Melnyk, S. A. (1998), "The scientific theory-building process: a primer using the case of TQM", Journal of Operations Management, Vol. 16 No. 4, pp. 322-339.

- Harrison, J. S., Wicks, A. C. (2013). Stakeholder theory, value, and firm performance. Business ethics quarterly, 23(1), 97-124.

- Henri, J. F. (2006). Management control systems and strategy: A resource-based perspective. Accounting, organizations and society, 31(6), 529-558.

- Horváth, D., Szabó, R.Z., (2019). Driving forces and barriers of Industry 4.0: Do multinational and small and medium-sized companies have equal opportunities?. Technological Forecasting and Social Change, 146, pp.119-132.

- Ittner, C. D., Larcker, D. F. (2001). Assessing empirical research in managerial accounting: a value-based management perspective. Journal of accounting and economics, 32(1-3), 349-410.

- Ittner, C. D., Larcker, D. F., Randall, T. (2003). Performance implications of strategic performance measurement in financial services firms. Accounting, organizations and society, 28(7-8), 715-741.

- Jeble, S., Kumari, S., Venkatesh, V.G., Singh, M. (2019), "Influence of big data and predictive analytics and social capital on performance of humanitarian supply chain: Developing framework and future research directions", Benchmarking: An International Journal, Vol. 27 No. 2, pp. 606-633.

- $\quad$ Kamble, S. S., Gunasekaran, A., Ghadge, A., Raut, R. (2020). A performance measurement system for industry 4.0 enabled smart manufacturing system in SMMEs-A review and empirical investigation. International Journal of Production Economics, 229, 107853.

- $\quad$ Ketchen, Jr, D. J., Hult, G. T. M. (2011). Building theory about supply chain management: some tools from the organizational sciences. Journal of Supply Chain Management, 47(2), 12-18.

- Kibira, D., Kibira, D., Kumaraguru, S., Morris, K. C. (2015). Methods and tools for performance assurance of smart manufacturing systems. US Department of Commerce, National Institute of Standards and Technology.

- Klovienè, L., Uosytė, I. (2019). Development of Performance Measurement System in the Context of Industry 4.0: a Case Study. Engineering Economics, 30(4), 472-482. 
- Kotkova Striteska, M., Zapletal, D., (2020). The Role of Corporate Culture in Performance Measurement and Management Systems. International Journal of Financial Studies, 8(4), p.75.

- Lambert, R. A. (2001). Contracting theory and accounting. Journal of accounting and economics, 32(13), 3-87.

- Lee, T.W., Mitchell, T.R., Sablynski, C.J., (1999). Qualitative research in organizational and vocational psychology, 1979-1999. Journal of vocational behavior, 55(2), pp.161-187.

- Leuschner, R., Rogers, D. S., Charvet, F. F. (2013). A meta-analysis of supply chain integration and firm performance. Journal of Supply Chain Management, 49(2), 34-57.

- Liao, Y., Deschamps, F., Loures, E., Ramos, L.F.P. (2017). Past, present and future of Industry 4.0 - a systematic literature review and research agenda proposal. International Journal of Production Research, 55(12), pp.3609-3629.

- Lucianetti, L., Jabbour, C. J. C., Gunasekaran, A., Latan, H. (2018). Contingency factors and complementary effects of adopting advanced manufacturing tools and managerial practices: Effects on organizational measurement systems and firms' performance. International Journal of Production Economics, 200, 318-328.

- Melnyk, S. A., Stewart, D. M., Swink, M. (2004). Metrics and performance measurement in operations management: dealing with the metrics maze. Journal of operations management, 22(3), 209-218.

- Modell, S., (2019). Constructing institutional performance: a multi-level framing perspective on performance measurement and management. Accounting and Business Research, 49(4), pp.428-453.

- Mohammadi, S., Haniff, A.P., Bititci, U.S., (2018). Performance measurement and management in temporary organisations: An organisational control theory perspective. In 25th Annual EurOMA Conference 2018.

- Mura, M., Longo, M., Micheli, P., Bolzani, D., (2018). The evolution of sustainability measurement research. International Journal of Management Reviews, 20(3), pp.661-695.

- Neely, A. (2005). The evolution of performance measurement research: developments in the last decade and a research agenda for the next. International Journal of Operations \& Production Management, 25(12), 1264-1277.

- Nudurupati, S. S., Garnego, P., Bititci, U. S. (2020). Impact of the changing business environment on performance measurement and management practices. International Journal of Production Economics, 107942.

- Oses, N., Legarretaetxebarria, A., Quartulli, M., García, I., Serrano, M. (2016). Uncertainty reduction in measuring and verification of energy savings by statistical learning in manufacturing environments. International Journal on Interactive Design and Manufacturing (IJIDeM), 10(3), 291-299.

- Okwir, S., Nudurupati, S.S., Ginieis, M., Angelis, J., 2018. Performance measurement and management systems: a perspective from complexity theory. International Journal of Management Reviews, 20(3), pp.731-754.

- Pinto, J., 2019. Key to effective organizational performance management lies at the intersection of paradox theory and stakeholder theory. International Journal of Management Reviews, 21(2), pp.185208.

- Raj, A., Dwivedi, G., Sharma, A., de Sousa Jabbour, A., Rajak, S., (2020). Barriers to the adoption of industry 4.0 technologies in the manufacturing sector: An inter-country comparative perspective. International Journal of Production Economics, 224, p.107546.

- Rogers, P.R., Miller, A. and Judge, W.Q., 1999. Using information-processing theory to understand planning/performance relationships in the context of strategy. Strategic management journal, 20(6), pp.567-577.

- Sahlin, J., Angelis, J. (2019). Performance management systems: reviewing the rise of dynamics and digitalization. Cogent Business \& Management, 6(1), 1642293.

- Sardi, A., Sorano, E., Cantino, V. and Garengo, P. (2020). Big data and performance measurement research: trends, evolution and future opportunities. Measuring Business Excellence, Vol. ahead-of-print No. ahead-of-print.

- Seuring, S, Yawar, S, Land, A, Raja, UK \& Sauer, P 2020, 'The application of theory in literature reviews - illustrated with examples from supply chain management', International Journal of Operations and Production Management, vol. 41, no. 1, pp. 1-20.

- Shook, N. J., Fazio, R. H. (2009). Political ideology, exploration of novel stimuli, and attitude formation. Journal of Experimental Social Psychology, 45(4), 995-998. 
- Smith, M. and Bititci, U.S. (2017). Interplay between performance measurement and management, employee engagement and performance. International Journal of Operations \& Production Management, Vol. 37 No. 9, pp. 1207-1228.

- Stern, R.N., Pfeffer, J., Salancik, G. (1979). The External Control of Organizations: A Resource Dependence Perspective. Contemporary Sociology, 8(4), p.612.

- Strzelczak, S. (2018). Performance Measurement in Production Internet: An Ecosystemic Perspective. IFAC-PapersOnLine, 51(11), 796-802.

- Taticchi, P., Garengo, P., Nudurupati, S. S., Tonelli, F., Pasqualino, R. (2015). A review of decisionsupport tools and performance measurement and sustainable supply chain management. International Journal of Production Research, 53(21), 6473-6494.

- Taticchi, P., Tonelli, F., Cagnazzo, L. (2010). Performance measurement and management: a literature review and a research agenda. Measuring business excellence, 14(1), 4-18.

- Tatikonda, M. V., Montoya-Weiss, M. M. (2001). Integrating operations and marketing perspectives of product innovation: The influence of organizational process factors and capabilities on development performance. Management science, 47(1), 151-172.

- Taylor, A., Taylor, M., (2014). Factors influencing effective implementation of performance measurement systems in small and medium-sized enterprises and large firms: a perspective from Contingency Theory. International Journal of Production Research, 52(3), pp.847-866.

- Touboulic, A., Walker, H. (2015). Theories in sustainable supply chain management: a structured literature review. International Journal of Physical Distribution \& Logistics Management, 45(1/2), pp.1642.

- Tranfield, D., Denyer, D., Smart, P. (2003). Towards a methodology for developing evidence-informed management knowledge by means of systematic review. British journal of management, 14(3), 207-222.

- Wadongo, B. and Abdel-Kader, M. (2014). Contingency theory, performance management and organisational effectiveness in the third sector: A theoretical framework. International Journal of Productivity and Performance Management, Vol. 63 No. 6, pp. 680-703.

- Walker, H., Chicksand, D., Radnor, Z. and Watson, G. (2015). "Theoretical perspectives in operations management: an analysis of the literature", International Journal of Operations \& Production Management, Vol. 35 No. 8, pp. 1182-1206.

- Wang, J., Hou, C. C., Lin, P. C. (2013). Two-phase assessment for the environmental impacts from offset lithographic printing on color-box packaging. Journal of cleaner production, 53, 129-137.

- Wernerfelt, B. (1984). A resource-based view of the firm. Strategic management journal, 5(2), 171-180.

- Williamson, O. E. (1971). The vertical integration of production: market failure considerations. The American Economic Review, 61(2), 112-123. 


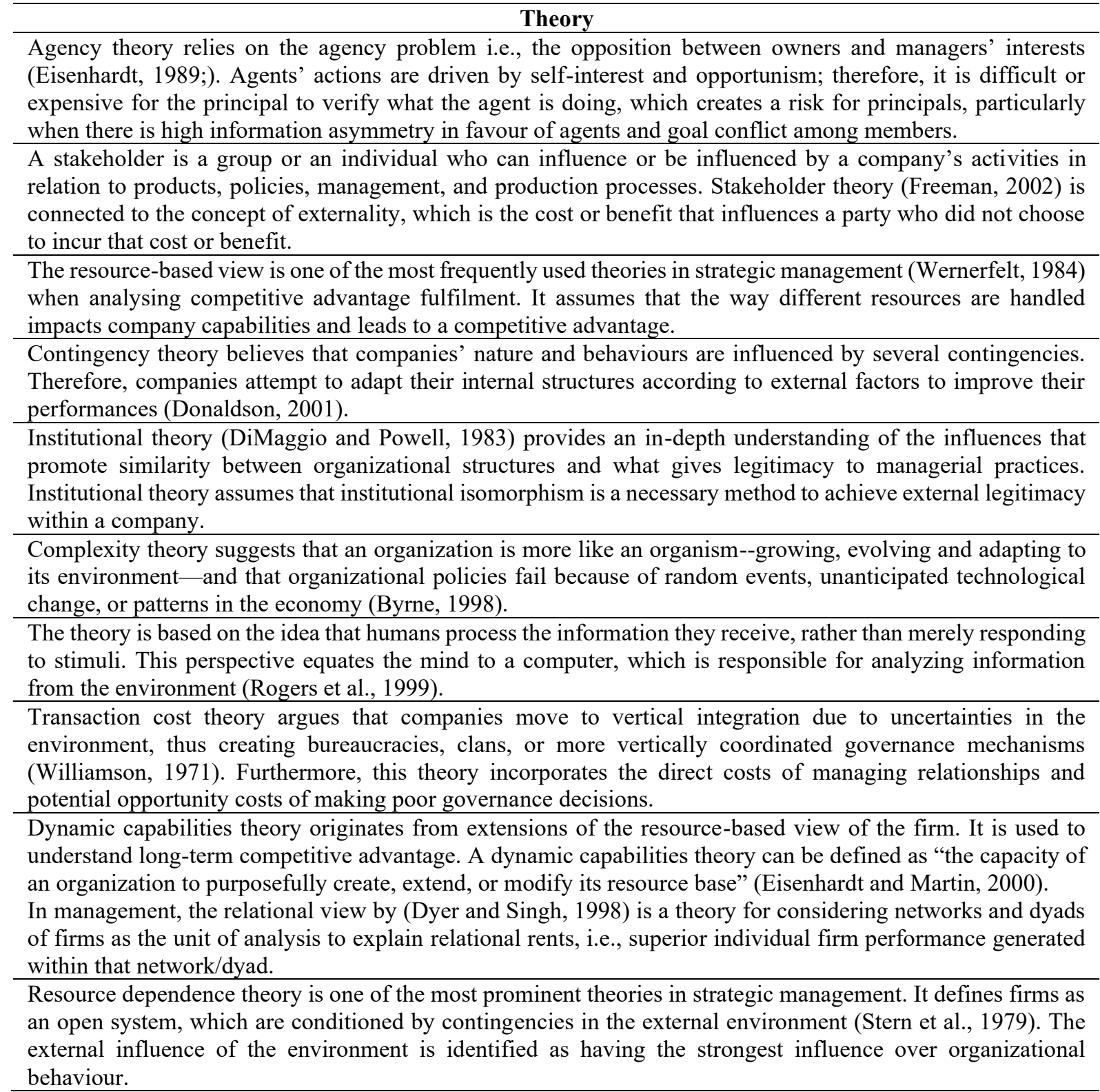

Table A1- Overview of the most relevant theories for PMM 